\title{
A Compact Bow-tie Shaped Wide-band Microstrip Patch Antenna for Future 5G Communication Networks
}

\author{
Deven G. PATANVARIYA, Anirban CHATTERJEE \\ Dept. of Electronic and Communication Engineering, National Institute of Technology Goa, Goa, India \\ devenpatanvariya@nitgoa.ac.in,snanirban@nitgoa.ac.in \\ Submitted October 6, 2020 / Accepted December 16, 2020
}

\begin{abstract}
In this paper, a novel compact bow-tie shaped microstrip patch antenna for wide-band application is presented. The proposed geometry consists of a modified bow-tie structure at the top of the Rogers RT-5880 substrate with a $50 \Omega$ feed-line and $8 \times 8 \mathrm{~mm}^{2}$ full groundplane. The diagonal slots inside the geometry have been implemented for exact resonating. The circuit analysis and various parametric analyses of the proposed geometry have been studied. The prototype of the antenna resonates at $27.77 \mathrm{GHz}$. The antenna has a fractional bandwidth of $6.77 \%(26.81-28.69 \mathrm{GHz})$ in simulation and $6.30 \%$ (26.89-28.64 GHz) in measurement respectively. The measured linear gain and radiation efficiency of the antenna are $7.00 \mathrm{dBi}$ and $74 \%$ respectively. Also, it has a low sidelobe-level and cross-polarization level over the entirespace. The proposed wide-band antenna gives good timedomain characteristics as well as provides an acceptable FBR and impedance matching over the resonating band. All the properties suggest that the proposed antenna suits well for $5 G$ communication along with various wireless systems.
\end{abstract}

\section{Keywords}

Bow-tie shape, microstrip patch antenna, 5G communication, millimeter wave

\section{Introduction}

Due to the mobile wireless technology era, the rapid developments is occurred in mobile communication from $0^{\text {th }}$ Generation to $4^{\text {th }}$ Generation. Recent development in $4 \mathrm{G}$ technology has several uses, like machine communication, remote host observing, and video call data. It has many applications but is not able to solve the problem of weak coverage, bad quality, poor connections, and inter-connectivity. To meet the high data rates, mobile communication needs to promote the next generation (5G) [1]. The millimeter band has been used for the $5 \mathrm{G}$ mobile communications. Some of the estimated bands suggested for $5 \mathrm{G}$ communications are $28 \mathrm{GHz}, 33 \mathrm{GHz}$, and many more [1-2]. To fulfill the re- quired criteria, the microstrip patch antennas are a suitable approach. For practical applications, the size of the antenna and bandwidth is the major concern for antenna designers.

Microstrip patch antenna has many advantages like easy fabrication, low cost, small size, and high efficiency [3, 4]. Furthermore, fractal geometry has been used for antenna size reduction [5]. In [6], the authors presented the Sierpinski fractal-based bow-tie antenna geometry for high directivity and small size. The bow-tie geometry has a symmetric property which helps to improve the radiation pattern. The authors of [7] reported the bow-tie geometry's application for GPS pipe detection. The $28 \mathrm{GHz}$ millimeter-wave application, designing compact antennas is a challenging issue since reducing the dimensions of the ground plane shortens the current length path thereby resulting in the poor antenna matching at lower frequencies. In this regard, many millimeter-wave wide-band antennae have been reported in the literature [8-17]. Apart from size, the cross-polarization level of the antenna should be as low as possible to reduce the interference for better communication between the devices. Consequently, the antenna gains have to improve to mitigate the effect of the free space path loss at the mmwave band. For this purpose, the antenna array with beam steering in the desired direction and low sidelobe level (SLL) array can be used $[8,9,14,16]$. Many critical limitations present in designing wide-band antennas array for smaller mobile terminals in conjunction with good directivity and better impedance bandwidth. The proposed antenna design incorporates the major requisites for meeting the present requirements of a feasible wide-band system.

In this paper, a compact wide-band bow-tie shaped antenna geometry with good radiation pattern for $5 \mathrm{G}$ mobile communications has been presented. The resonating frequency of the antenna is $27.75 \mathrm{GHz}$. The proposed bow-tie antenna has a symmetric structure. The equivalent circuit diagram of the proposed bow-tie antenna is studied, in which the antenna acts as a parallel RLC load and a microstrip line as $\mathrm{T} / \mathrm{Pi}$ matching network $[18,19]$. The various parametric analysis of the geometry has been done by using Computer simulation technology (CST)-Microwave studio suite [20] and circuit analysis is simulated by using Cadence-virtuoso. The simulated and measured radiation pattern, the reflection 


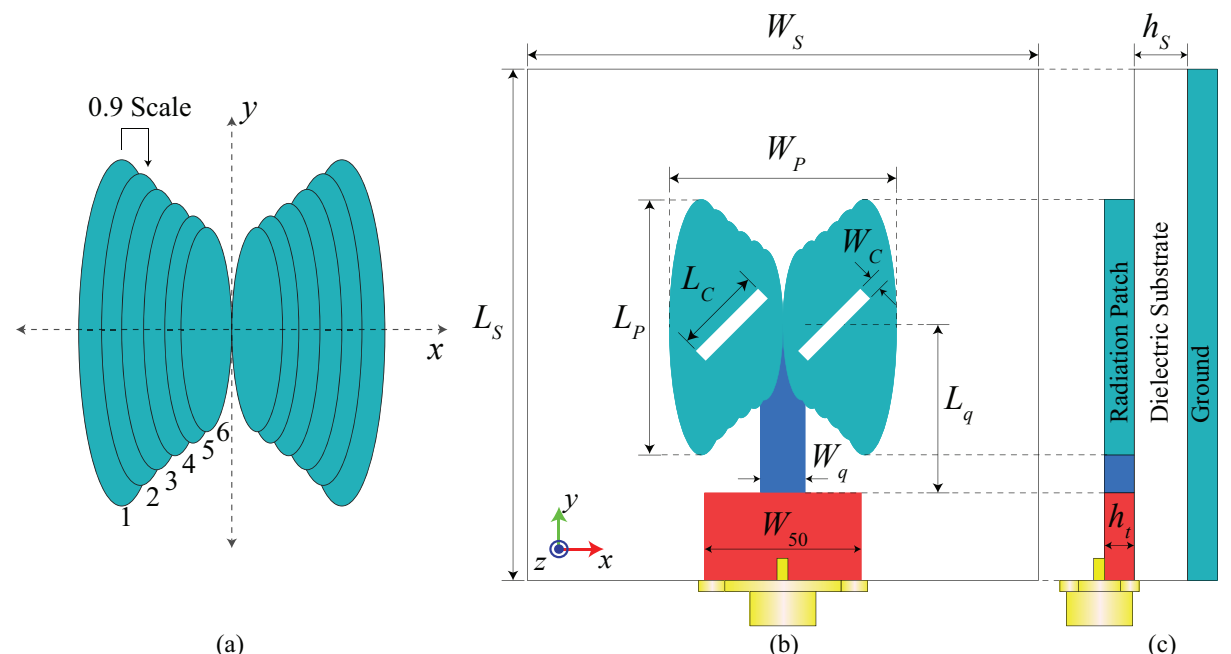

Fig. 1. (a) Step formation of the proposed bow-tie geometry, (b) Proposed antenna Front-view, (c) Side-view. Dimensions (unit:mm): $W_{\mathrm{S}}=8.00$, $L_{\mathrm{S}}=8.00, W_{\mathrm{P}}=3.55, L_{\mathrm{P}}=3.95, W_{\mathrm{C}}=0.04, L_{\mathrm{C}}=1.20, W_{\mathrm{q}}=0.70, L_{\mathrm{q}}=2.69, h_{\mathrm{S}}=0.787, h_{\mathrm{t}}=0.017, W_{50}=2.42$.

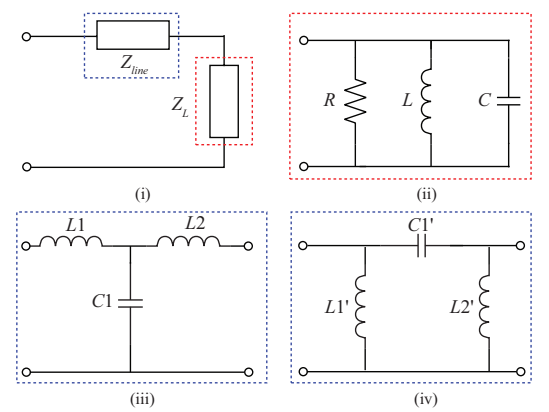

(a)

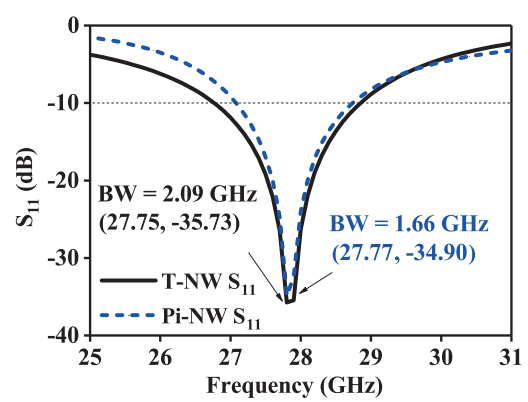

(b)

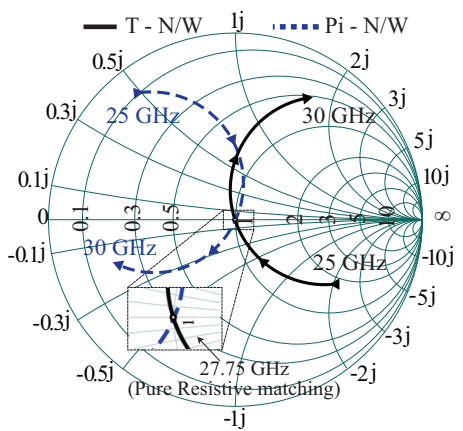

(c)

Fig. 2. (a) Equivalent circuit diagram of antenna (i)-(iv): Antenna as RLC Load, $T$ and Pi network, (b) $S_{11}$ response, (c) Input impedance response. Parametric value of the components: $R=50.53 \Omega, L=0.222 \mathrm{nH}, C=0.147 \mathrm{pF}, L 1=1.50 \mathrm{nH}, L 2=1.50 \mathrm{nH}, C 1=0.042 \mathrm{pF}, L 1^{\prime}=0.055 \mathrm{nH}$, $L 2^{\prime}=0.055 \mathrm{nH}, C 1^{\prime}=0.308 \mathrm{pF}$.

coefficient as well as the front-to-back ratio (FBR) of the proposed geometry suits well for the $5 \mathrm{G}$ communication system. Furthermore, the proposed antenna's time-domain characteristics have been simulated and investigated and different analyses such as group delay, phase response, and isolation $\mathrm{S}_{21}$ have been done. The stable radiation pattern as well as perfect impedance matching and good time-domain characteristics have been observed over the entire resonating band of the proposed wide-band antenna.

The rest of the paper is organized as follows. Wideband antenna configuration and circuit analysis have been described in Sec. 2. Section 3 discusses the antenna experimental results, prototype, parametric analysis, E-field distribution, radiation pattern, and time-domain characteristics. Section 4 gives the conclusion.

\section{Wide-band Antenna Configuration}

The procedure of radiating antenna design includes the geometry of antenna, feeding techniques, and the match- ing element is described in this section. The symmetric radiation pattern as well as directive gain from the antenna has been achieved by making symmetric geometry. The step formation of the proposed bow-tie geometry is shown in Fig. 1(a). Initially, the single oval shape which is indicated as 1 is considered and it is shown in Fig. 1(a). The next oval shapes are scaled down by 0.9 to the previous oval shapes and combined with all 6 oval shapes to make singleside geometry. Now, for the symmetry structure take mirror symmetry of the combined oval geometry over the vertical axis. Finally, the proposed bow-tie shaped geometry has been illustrated in Fig. 1(a).

The bow-tie geometry is placed on the top layer of the dielectric substrate Rogers RT-5880 having $\epsilon_{\mathrm{r}}=2.2$ and $\tan \delta=0.0009$, which is shown in Fig. 1(b) [21]. The impedance matching between $50 \Omega$ and antenna, the quarter wavelength $\left(L_{\mathrm{q}}\right)$ transmission line has been implemented. The top view and side view of the bow-tie antenna is depicted in Fig. 1(b) and (c), respectively. The thickness of the dielectric material is $0.787 \mathrm{~mm}$ and copper layers thickness is $0.017 \mathrm{~mm}$. The diagonal slots inside the geometry have been 
etched to resonate the structure at $27.75 \mathrm{GHz}$. The area of the full ground plane is $8 \times 8 \mathrm{~mm}^{2}$. The maximum length of the radiating patch is $3.95 \mathrm{~mm}$. The overall size of the patch antenna is $3.55 \times 3.95 \times 0.821 \mathrm{~mm}^{3}$. The detailed dimensions of the proposed geometry are given in Fig. 1. The formula relating the resonating frequency with side length is [3]:

$$
f=\frac{c_{0}}{2 L_{\mathrm{P}} \sqrt{\epsilon_{\mathrm{eff}}}}
$$

where $c_{0}$ is the free space light velocity, $f$ is the resonating frequency of the antenna, $\epsilon_{\mathrm{eff}}$ is the effective dielectric constant of the substrate, $L_{\mathrm{P}}$ is the side length of the geometry.

\subsection{Circuit Analysis}

The lumped equivalent circuit model of the proposed bow-tie antenna is illustrated in Fig. 2. In Fig. 2(a), the $Z_{\text {line }}$ is nothing but $\mathrm{T}$ or $\mathrm{Pi}$ matching network, and $Z_{\mathrm{L}}$ is antenna as parallel RLC load. The value of the Resistance $(R)$, Inductance $(L)$ and Capacitance $(C)$ can be calculated by the following equations (2-5):

$$
\begin{gathered}
C=\frac{W_{\mathrm{P}} L_{\mathrm{P}} \epsilon_{o} \epsilon_{\mathrm{eff}}}{2 h_{\mathrm{S}}}, \\
R=\frac{Q}{c_{0} \omega_{\mathrm{r}}}, \\
L=\frac{1}{c_{0} \omega_{\mathrm{r}}^{2}}, \\
Q=\frac{c_{0} \sqrt{\epsilon_{\mathrm{eff}}}}{\kappa f h_{\mathrm{S}}} .
\end{gathered}
$$

Here $W_{\mathrm{P}}$ is the width of the proposed geometry. $\kappa$ is the constant and $Q$ is the quality factor. The $R, L$, and $C$ values are listed in Fig. 2. The load impedance becomes $Z_{\mathrm{L}}=(0.999+\mathrm{j} 0.002) \Omega$. The characteristic impedance of the transmission line is approximately $50 \Omega$. The equivalent circuit of the feed line is derived by considering $\mathrm{T}$ or $\mathrm{Pi}$ networks. The reason for choosing T/Pi equivalent network for the feed line is to keep similar type behavior in the $S_{11}$ parameter between the equivalent circuit and the proposed patch antenna [8].

The complete circuit equivalent models of an antenna having a T/Pi network followed by parallel RLC load are shown in Fig. 2(a)(i-iv). The total impedance of the circuit, while the $\mathrm{T}$ matching network is of $Z_{T N / w}=(1.009+j 0.0016) \Omega$ and for the Pi matching network is of $Z_{\mathrm{PiN} / \mathrm{w}}=(1.007-\mathrm{j} 0.0075) \Omega$ at resonating frequency. The component values of T/Pi networks are computed from the Smith Chart. All the equivalent circuit models of the single element have been simulated using Cadence software. The $\mathrm{S}_{11}$ parameter of T/Pi networks are shown in Fig. 2(b), which resonates at a frequency of $27.75 \mathrm{GHz}$ with satisfactory bandwidth and return loss. The reason for getting larger bandwidth in the circuit model is the effect of fringing fields, dielectric material, and ground in the actual antenna are neglected in the model. The input impedance response of the network in the smith chart is illustrated in Fig. 2(c). It can be seen that the curve is passing through the center which indicates pure resistive matching at the resonating frequency.

\section{Result and Discussions}

The proposed bow-tie antenna is designed and simulated using CST MWS-18 using a finite integration technique (FIT). The proposed element has been fabricated and tested, as well as the simulated and measured results of the antenna have been discussed in this section. All the obtained results satisfy the minimum criteria for the $5 \mathrm{G}$ communications.

\subsection{Prototype and $S_{11}$}

The proposed bow-tie antenna has been fabricated and the prototype is shown in Fig. 3. Figure 4(a) illustrates the $\mathrm{S}_{11}$ parameter of the proposed antenna simulated by the CST software and measured by using the vector network analyzer (VNA). The simulated and measured resonating frequency is $27.75 \mathrm{GHz}$ and $27.77 \mathrm{GHz}$ respectively. The $10 \mathrm{~dB}$ impedance bandwidth of the antenna is $1.88 \mathrm{GHz}$ and $1.75 \mathrm{GHz}(26.89-28.64 \mathrm{GHz})$ with return losses of $<-10 \mathrm{~dB}$ respectively. The proposed geometry evaluation step effects on the $S_{11}$ parameter has been shown in Fig. 4(b). It can be seen from Fig. 4(b) that the Ant.-1 which is conventional rec. antenna is resonating at $30.00 \mathrm{GHz}$. The Ant.-2 and Ant.-3 which are left-bow and right-bow respectively resonate at $29.50 \mathrm{GHz}$ with good impedance bandwidth. The Ant.-4 which is proposed geometry without diagonal slots resonates at $28.00 \mathrm{GHz}$. According to the Fig. 4(b), modification in the geometry causes the frequency to shift to lower value with acceptable $S_{11}$ and impedance bandwidth. Finally, after etching the slots in the geometry, the Ant -5 which is proposed geometry resonates at $27.75 \mathrm{GHz}$. On the other hand, the proposed structure implemented on different substrate materials such as Neltec, FR-4 and Rogers RT-6010LM as well as its effect on the $S_{11}$ has been plotted in Fig. 4(c). It can be observed that the proposed bow-tie geometry can be implemented on any substrate material and it gives good $S_{11}$ characteristics as well as sufficient impedance bandwidth.

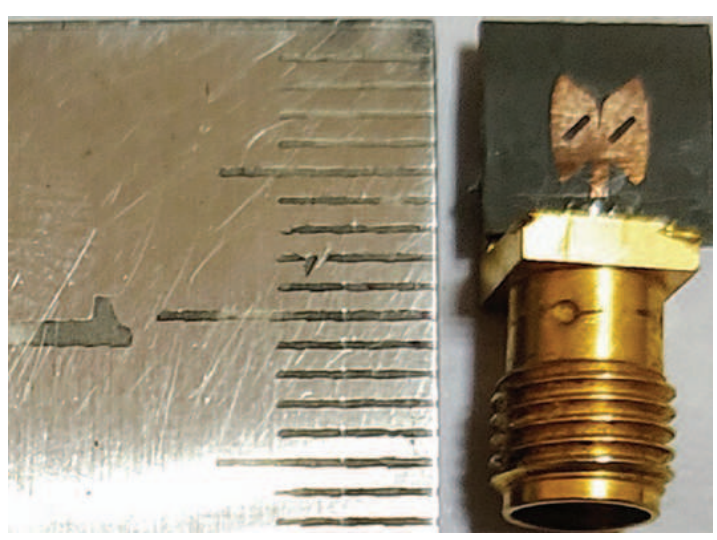

Fig. 3. Proposed antenna prototype. 


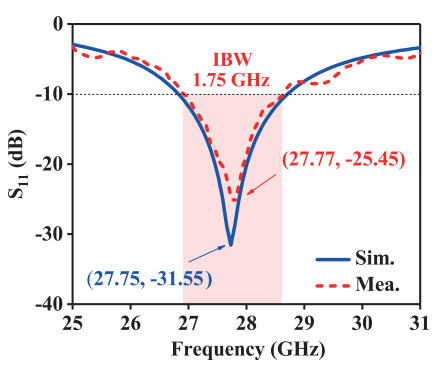

(a)

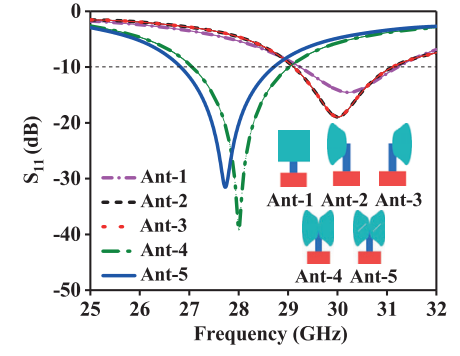

(b)

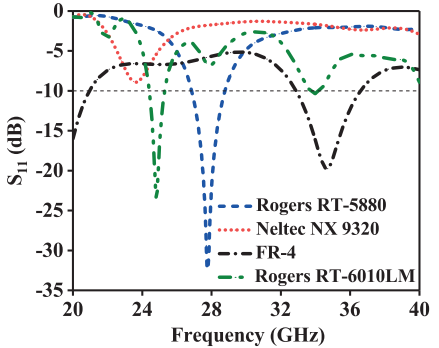

(c)

Fig. 4. (a) Simulated vs measured $S_{11}$ of proposed antenna. (b) Geometry evaluation $S_{11}$ response. (c) Effect on $S_{11}$ with different substrate.

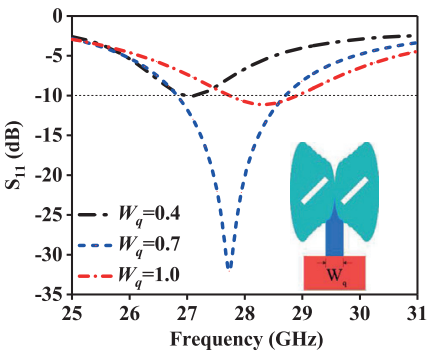

(a)

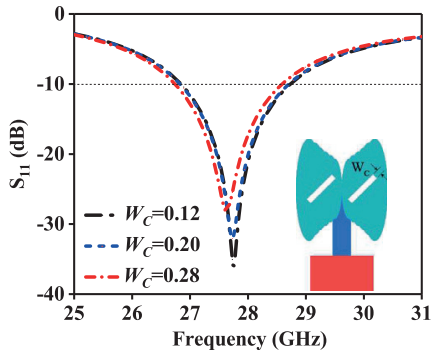

(b)

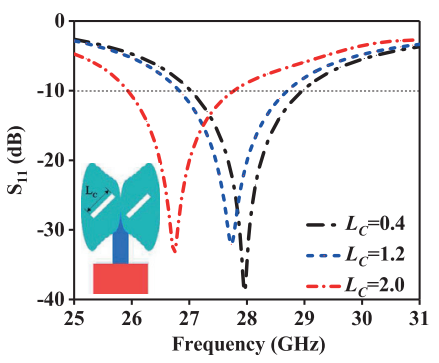

(c)

Fig. 5. Effect on $S_{11}$ : (a) $W_{\mathrm{q}}$ variation. (b) $W_{\mathrm{C}}$ variation. (c) $L_{\mathrm{C}}$ variation (unit: $\mathrm{mm}$ ).

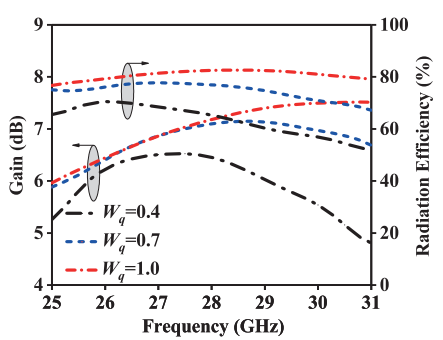

(a)

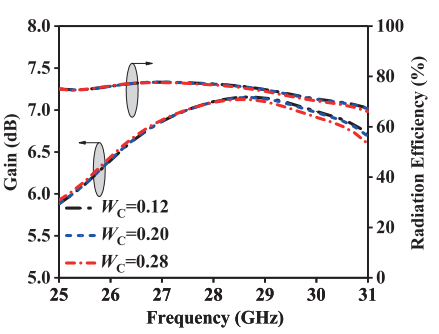

(b)

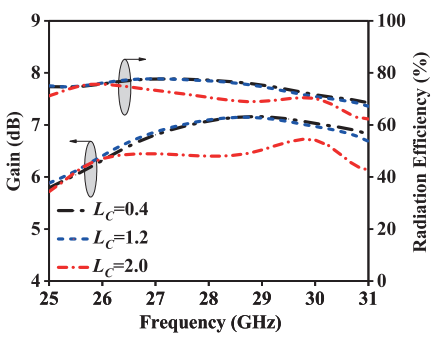

(c)

Fig. 6. Effect on gain and radiation efficiency: (a) $W_{\mathrm{q}}$ variation. (b) $W_{\mathrm{C}}$ variation. (c) $L_{\mathrm{C}}$ variation (unit: mm).

For the Rogers RT-5880 substrate, the proposed geometry resonates at $27.75 \mathrm{GHz}$ with acceptable results. Furthermore, the resonating frequency and impedance bandwidth of the proposed geometry can be controlled by changing the number of oval shapes in the geometry as well as the reduction scale factor.

\subsection{Parametric Analysis}

The experiment has been carried out by performing the parametric analysis of the proposed geometries. These analysis has been done by observing the $S_{11}$ parameter, gain, and radiation efficiency, which are the important parameters to design any practical antenna. Fig. 5(a) shows the variation in the $W_{\mathrm{q}}$ from $0.4 \mathrm{~mm}$ to $1.0 \mathrm{~mm}$, there is a drastic effect on the resonating frequency. The perfect resonating has been obtained for $W_{\mathrm{q}}=0.7 \mathrm{~mm}$. The diagonal slots width and length variations have been done and it is shown in Fig. 5(b) and (c) respectively. It can be seen that the value of $W_{C}=0.20 \mathrm{~mm}$ and $L_{\mathrm{C}}=1.2 \mathrm{~mm}$ the exact resonating has been achieved.
For the same value of the $W_{\mathrm{q}}$, the antenna gain and radiation efficiency have been simulated and it is shown in Fig. 6(a). As seen from Fig. 6(a), an increase in $W_{\mathrm{q}}$ value increases the gain and radiation efficiency. Similarly, for the $W_{\mathrm{C}}$ as well as $L_{\mathrm{C}}$ variation the gain and radiation efficiency results has been plotted in Fig. 6(b) and (c) respectively.

\subsection{Axial Ratio and E-field Distribution}

The circularly polarized left-bow and right-bow antennas $\mathrm{CP}$ gain as well as axial ratio characteristics have been simulated and plotted in Fig. 7(a). The left-bow structure has a LHCP gain of $4.92 \mathrm{dBic}$ and the same for the right-bow antenna as both antennae are identical. The axial ratio of both antennas is $1.24 \mathrm{~dB}$ and $\mathrm{CP}$ bandwidth is $3.37 \mathrm{GHz}$. The simulated left-bow and right-bow antennas radiation pattern in the different xz-plane and yz-plane has been illustrated in Fig. 7(b) and (c) respectively. It can be seen from the Fig. 7(b) that the left-bow has a higher left magnitude than the right magnitude. Similarly, the radiation pattern of the 


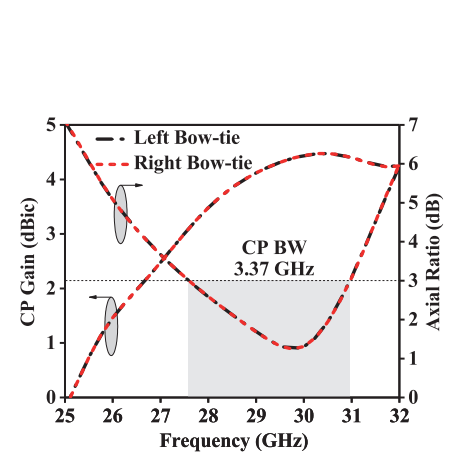

(a)

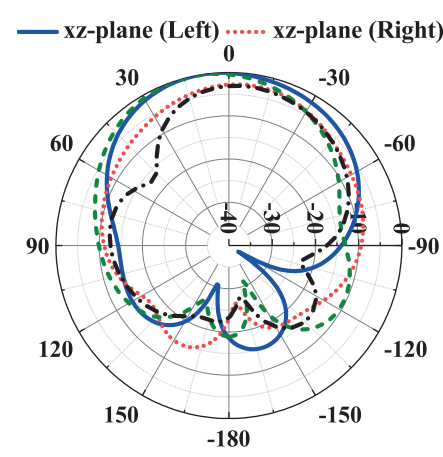

(b)

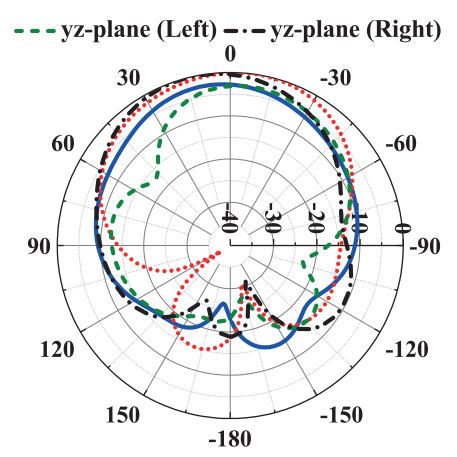

(c)

Fig. 7. (a) Left- and right-bow antennas CP gain and axial ratio. (b) Left-bow antenna radiation pattern. (c) Right-bow antenna radiation pattern.

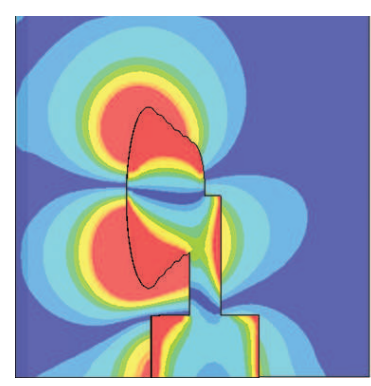

(a)

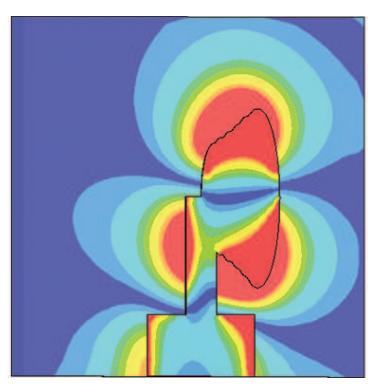

(b)

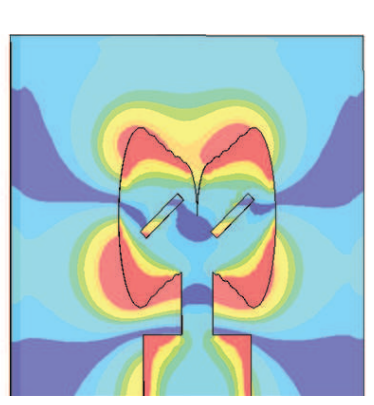

(c)

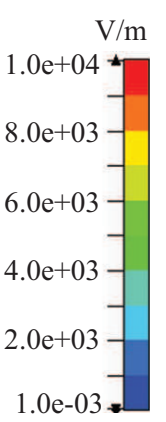

$1.0 \mathrm{e}-03$

Fig. 8. Electric-field distribution: (a) Left-bow antenna. (b) Right-bow antenna. (c) Proposed patch antenna.

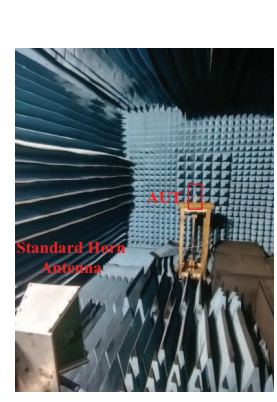

(a)

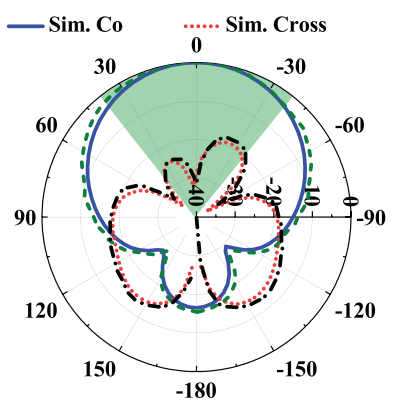

(b)

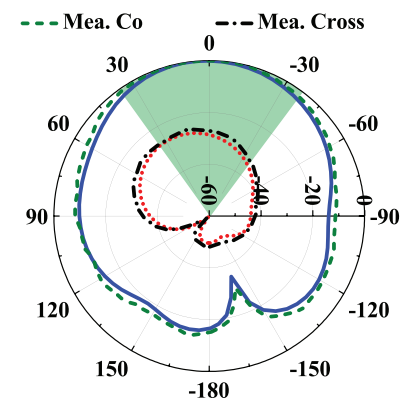

(c)

Fig. 9. Simulated and measured radiation pattern of the proposed antenna: (a) Measurement setup. (b) xz-plane. (c) yz-plane.

right-bow antenna is depicted in Fig. 7(c). The electric field (E-field) distribution in the proposed wide-band antennas has been simulated and illustrated in Fig. 8.

The E-field distribution in the left-bow structure is depicted in Fig. 8(a) and it can be observed that the E-field vectors are rotated in a clockwise direction which ensures the left circularly polarized element. Similarly, for the right-bow structure, the E-field distribution is illustrated in Fig. 8(b) and it can be seen that the E-field vectors are rotated in a counterclockwise direction which ensures the right circularly polarized element. The E-field radiated in the proposed wide-band bow-tie antenna is nearly linear polarized with its E-field vectors along the antenna's long axis as shown in Fig. 8(c). Therefore the proposed bow-tie shaped geometry is linearly polarized which is the superposition of left and right circular polarization.

\subsection{Radiation Pattern and Linear Gain}

The antenna measurement setup in an anechoic chamber is given in Fig. 9(a). The farfield radiation pattern [22] of the antennas for phi $=0^{\circ}$ and $90^{\circ}$ cuts are measured inside an anechoic chamber. The Antenna Under Test (AUT) has been aligned with a Standard Horn Antenna (Tx) and placed on top of the rotating table at a reasonable distance away from Tx. The measurements are taken at a step of $5^{\circ}$ from $0^{\circ}$ to $360^{\circ}$ for xz-plane and yz-plane conditions. The simulated and measured radiation pattern of the proposed structure in xz-plane and yz-plane have been illustrated in Fig. 9(b) and (c) respectively. It can be seen from the Fig. 9(b) and (c) that the measured sidelobe-level is $-11.00 \mathrm{~dB}$ and $-10.20 \mathrm{~dB}$. Moreover, the measured Half-Power BeamWidth (HPBW) is $80^{\circ}$ and $75^{\circ}$ and it is indicated with shades respectively. The cross-polarization level is more than $-20 \mathrm{~dB}$ over the entire 


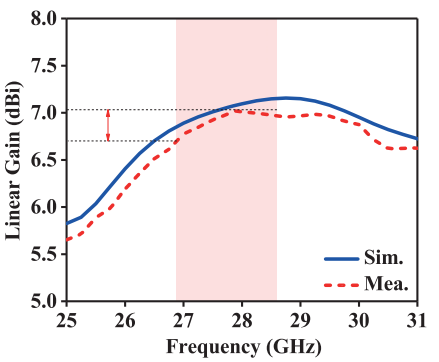

(a)

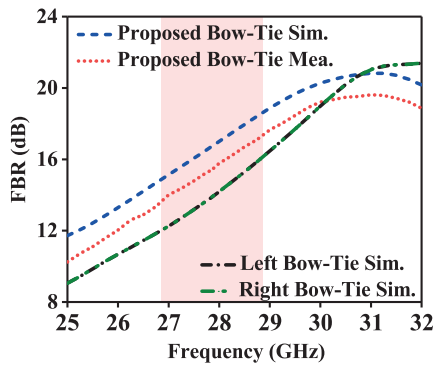

(b)

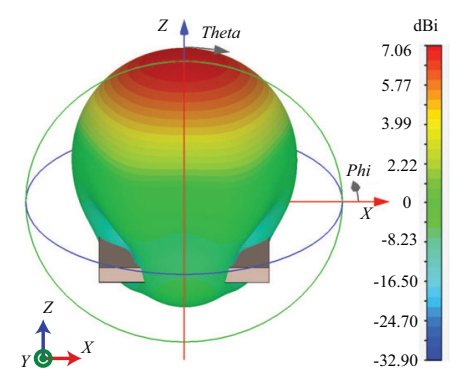

(c)

Fig. 10. (a) Simulated and measured linear gain. (b) FBR of antennas. (c) 3D radiation pattern of the proposed patch antenna.

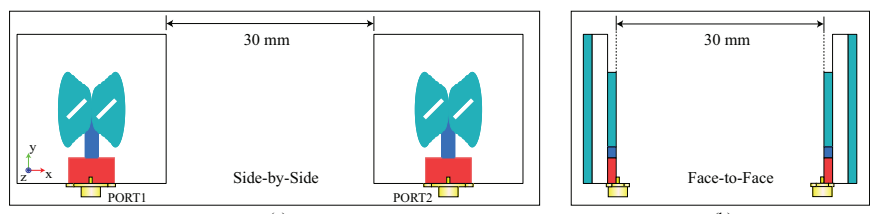

(a)

Fig. 11. The orientation of the proposed bow-tie antenna in CST environment to study the time-domain characteristics: (a) Side-by-Side. (b) Face-to-Face.

theta angle in both the planes. The simulated and measured directivity of the proposed wide-band antenna is $8.19 \mathrm{dBi}$ and $8.08 \mathrm{dBi}$ respectively. The Wheeler cap method [23] has been used to measure the radiation efficiency of the antenna. In the wheeler method, the prototype is kept inside the copper box and it is connected to the VNA to measure the $S_{11}$. The measured radiation efficiency of the proposed antenna is $74 \%$ (considering the reflection, conduction, and dielectric losses [3]). The performance of the fabricated prototype is almost the same and similar to the simulated structure. This endorses the good antenna characteristics as well as stability of the far-field pattern of the mm-wave antenna. The comparison of the simulated and measured linear gain of the proposed wide-band antenna geometry has been depicted in Fig. 10(a). The linear gain of the proposed antenna is measured by gain transformation method in the chamber [22]. The measured value of the linear gain is $7.00 \mathrm{dBi}$ over the resonating band. The simulated and measured front-to-back ratio (FBR) of the proposed antennas is shown in Fig. 10(b). For the left-bow and right-bow structures, the simulated FBR varies from 16 to $21 \mathrm{~dB}$ over the band. It is a magnitude ratio of the main lobe to the back lobe, the measured FBR value of proposed bow-tie antenna varies from 13 to $17 \mathrm{~dB}$ over the resonating band. The proposed directional antenna has a higher FBR which helps to overcome the signal interference and increases the range as well as the performance of the antennas. The FBR value of more than $15 \mathrm{~dB}$ has been obtained for the proposed bow-tie antenna. The simulated $3 \mathrm{D}$ radiation pattern of the proposed geometry is depicted in Fig. 10(c).

\subsection{Time Domain Characteristics}

The time-domain characteristics of the proposed bowtie antenna have been carried out to understand the group delay, phase response, and isolation characteristics of the antenna. The experiment has been done by fixing the same antenna at a distance of $30 \mathrm{~mm}$ in the CST MWS environment as illustrated in Fig. 11. The time-domain analysis has been simulated for two conditions: Side-by-Side (SS) condition and Face-to-Face (FF) condition. The antenna arrangement for both conditions has been depicted in Fig. 11(a) and (b), respectively and both antenna work as transceivers. The ratio of the negative rate of change of the phase transfer function with respect to frequency is defined as group delay and it can be calculated mathematically using following equation [24]:

$$
\tau_{\mathrm{g}}(\omega)=-\frac{\mathrm{d} \phi(f)}{2 \pi \mathrm{d} f}
$$

where $\phi$ is the received signal phase response. The group delay as well as phase response both are related to the gain response of the antenna. Furthermore, non-linear phases as well as pulse distortion has been received in the far-field which is due to the more than $1 \mathrm{n} \mathrm{sec}$ variation in the group delay. The group delay vs frequency analysis of the proposed antenna is shown in Fig. 12(a). It can be seen from the Fig. 12(a), that the group delay variation in SS condition is less than $0.40 \mathrm{n} \mathrm{sec}$, while in FF condition it is less than $0.48 \mathrm{n} \mathrm{sec}$ over the resonating band. The transfer function of the antenna is indicated as:

$$
H(\omega)=\sqrt{\frac{2 \pi c_{0} D S_{21}(\omega) \mathrm{e}^{\frac{\mathrm{j} \omega D}{c_{0}}}}{\mathrm{j} \omega}}
$$

where $D$ is the antennas distance [25]. The isolation between the two ports identifies the ratio of power incident on one port and the power delivered to another port when it is terminated by a matched load. Also, it gives the coupling parameter between the two ports. A large value of isolation promises uncorrelated transmission of electric signals on both ports. 


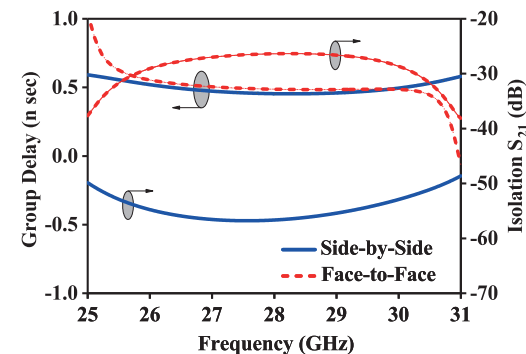

(a)

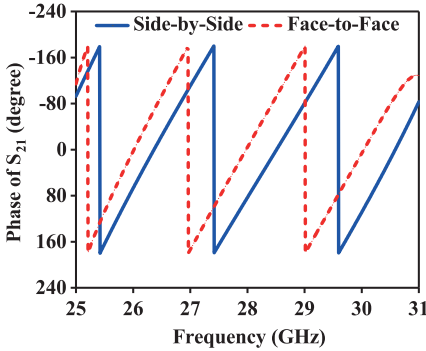

(b)

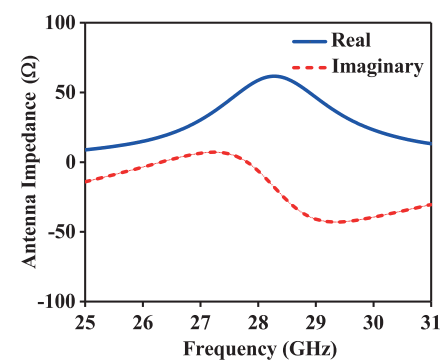

(c)

Fig. 12. Proposed antenna: (a) Group delay and isolation. (b) Phase response. (c) Antenna impedance response.

\begin{tabular}{|c|c|c|c|c|c|c|c|}
\hline $\begin{array}{c}\text { Ref. } \\
\text { antenna }\end{array}$ & $\begin{array}{c}\text { Resonating } \\
\text { frequency }(\mathrm{GHz})\end{array}$ & $\begin{array}{c}\text { Return loss } \\
(\mathrm{dB})\end{array}$ & $\begin{array}{c}\text { Bandwidth } \\
(\mathrm{GHz})\end{array}$ & $\begin{array}{c}\text { Gain } \\
(\mathrm{dBi})\end{array}$ & $\begin{array}{c}\text { Radiation } \\
\text { efficiency }(\%)\end{array}$ & $\begin{array}{c}\text { Size } \\
(\mathrm{mm})^{2}\end{array}$ & $\begin{array}{c}\text { No. of } \\
\text { port }\end{array}$ \\
\hline$[8]$ & 28.00 & -25.00 & 0.52 & 12.65 & 75.00 & $17.00 \times 17.00$ & $\begin{array}{c}4 \text { port, } \\
4 \text { elements }\end{array}$ \\
\hline$[9]$ & 28.30 & -38.00 & 1.50 & 7.20 & -- & $30.00 \times 19.90$ & $\begin{array}{c}\text { Single port, } \\
\text { Single element }\end{array}$ \\
\hline$[10]$ & 28.00 & -38.00 & 9.50 & 8.20 & -- & $30.00 \times 65.00$ & $\begin{array}{c}\text { Single port, } \\
4 \text { elements }\end{array}$ \\
\hline$[11]$ & 25.40 & -24.00 & 5.60 & 6.40 & 57.10 & $31.20 \times 31.20$ & $\begin{array}{c}8 \text { port, } \\
\text { Single element }\end{array}$ \\
\hline$[14]$ & 30.70 & -28.00 & 12.40 & 8.20 & $>80.00$ & $50.80 \times 12.00$ & $\begin{array}{c}4 \text { port, } \\
4 \text { elements }\end{array}$ \\
\hline$[15]$ & 28.00 & -40.00 & 1.30 & 7.60 & 85.60 & $6.00 \times 6.00$ & $\begin{array}{c}\text { Single port, } \\
\text { Single element }\end{array}$ \\
\hline$[16]$ & 27.00 & -25.00 & 7.25 & 14.10 & -- & $19.00 \times 19.00$ & $\begin{array}{c}4 \text { port, } \\
4 \text { elements }\end{array}$ \\
\hline $\begin{array}{c}\text { Proposed } \\
\text { Antenna }\end{array}$ & $\mathbf{2 7 . 7 7}$ & $\mathbf{- 2 5 . 4 5}$ & $\mathbf{1 . 7 5}$ & $\mathbf{7 . 0 0}$ & $\mathbf{7 4}$ & $\mathbf{8 . 0 0} \times \mathbf{8 . 0 0}$ & $\begin{array}{c}\text { Single port, } \\
\text { Single element }\end{array}$ \\
\hline
\end{tabular}

Tab. 1. Performance parameters comparison.

The isolation characteristics $\left(\mathrm{S}_{21}\right)$ of the proposed geometry have been simulated and it is shown in Fig. 12(a). For both conditions, the proposed geometry provides sufficient isolation which is more than $-25 \mathrm{~dB}$ over the resonating band. The phase response of the proposed antenna has been illustrated in Fig. 12(b). The proposed geometry gives the linear phase variation in SS and FF conditions, which indicates good time-domain characteristics of the proposed antenna. Furthermore, the linear phase variations for FF and SS conditions indicates the nonappearance of any out of phase element in the received signal. The input impedance of the proposed antenna has been shown in the Fig. 12(c). It is observed that the antenna has a high input impedance at $28.60 \mathrm{GHz}$, which indicates that the current flow has been interrupted there. The real part of the impedance is almost constant $50 \Omega$ over the resonating band. Finally, the performance of the proposed $28 \mathrm{GHz}$ millimeter wave wide-band antenna is compared with some other recently reported mm-wave antennas in Tab. 1 . It can be observed that the proposed bow-tie antenna outperformed in terms of size, gain, and bandwidth. The proposed antenna is suitable for the future $5 \mathrm{G}$ communication systems.

\section{Conclusion}

A small and high directivity bow-tie antenna is presented for $5 \mathrm{G}$ communication. The bow-tie geometry is designed on Rogers RT-5880 substrate which resonates at the millimeter-wave frequency. The lumped equivalent circuit with T/Pi matching network is resonating at the same frequency. A maximum directivity of $8.08 \mathrm{dBi}$ is achieved at $27.77 \mathrm{GHz}$ with a stable radiation pattern. The compact size structure has a low sidelobe-level and crosspolarization level in both the xz-plane and yz-plane. Also, it has a measured radiation efficiency of $74 \%$. The proposed geometry provides good time-domain characteristics as well as sufficient FBR and proper impedance matching over the resonating band. The single element has satisfied the minimum criteria for the $5 \mathrm{G}$ communication network. The gain can be further improved by incorporating more number of radiating elements in the structure.

\section{Acknowledgments}

This paper is an outcome of the Research work under the SERB Extra Mural Research Funding (File No.: SB/S3/EECE/226/2016), Department of Science and Technology, Government of India. 


\section{References}

[1] RAPPAPORT, T. S., SUN, S., MAYZUS R., et al. Millimeter wave mobile communications for 5G cellular: It will work. IEEE Access, 2013, vol. 1, p. 335-349. DOI: 10.1109/ACCESS.2013.2260813

[2] QUALCOMM TECHNOLOGIES INC. Spectrum for $4 G$ and 5G. [Online] Cited 2020-06-06. Available at: https://www.qualcomm.com/media/documents/files/spectrumfor-4g-and-5g.pdf

[3] BALANIS, C. A. Antenna Theory: Analysis and Design. 3rd ed., New York (USA): John Wiley \& Sons, 2005. ISBN: 978-0471667827

[4] GUHA, D., ANTAR, Y. M. Microstrip and Printed Antennas: New Trends, Techniques and Applications. Hoboken (USA): John Wiley \& Sons, 2010. ISBN: 978-0470973370

[5] MANDELBROT, B. B. The Fractal Geometry of Nature. New York (USA): WH Freeman, 1983. ISBN: 978-0716711865

[6] ANGUERA, J., PUENTE, C., BORIA, C., et al. Small and highdirectivity bow-tie patch antenna based on the Sierpinski fractal. Microwave and Optical Technology Letters, 2001, vol. 31, no. 3 , p. 239-241. DOI: $10.1002 / \mathrm{mop} .1407$

[7] SEYFRIED, D., JANSEN, R., SCHOEBEL, J. Shielded loaded bowtie antenna incorporating the presence of paving structure for improved GPR pipe detection. Journal of Applied Geophysics, 2014, vol. 111, p. 289-298. DOI: $10.1016 /$ j.jappgeo.2014.10.019

[8] KHALILY, M., TAFAZOLLI, R., RAHMAN, T. A., et al. Design of phased arrays of series-fed patch antennas with reduced number of the controllers for 28-GHz mm-wave applications. IEEE Antennas and Wireless Propagation Letters, 2015, vol. 15, p. 1305-1308. DOI: 10.1109/LAWP.2015.2505781

[9] PARK, J. S., KO, J. B., KWON, et al. A tilted combined beam antenna for $5 \mathrm{G}$ communications using a $28 \mathrm{-GHz}$ band. IEEE Antennas and Wireless Propagation Letters, 2016, vol. 15, p. 1685-1688. DOI: 10.1109/LAWP.2016.2523514

[10] YANG, B., YU, Z., DONG, Y., et al. Compact tapered slot antenna array for 5G millimeter-wave massive MIMO systems. IEEE Transactions on Antennas and Propagation, 2017, vol. 65, no. 12, p. 6721-6727. DOI: 10.1109/TAP.2017.2700891

[11] SHOAIB, N., SHOAIB, S., KHATTAK, I., et al. MIMO antennas for smart 5G devices. IEEE Access, 2018, vol. 6, p. 77014-77021. DOI: 10.1109/ACCESS.2018.2876763

[12] AW, M. S., ASHWATH, K., ALI, T. A compact two element MIMO antenna with improved isolation for wireless applications. Journal of Instrumentation, 2019, vol. 14, p. 1-16. DOI: $10.1088 / 1748-0221 / 14 / 06 / \mathrm{P} 06014$

[13] CHATTERJEE, A., MONDAL, T., PATANVARIYA, D. G., et al. Fractal-based design and fabrication of low-sidelobe antenna array. AEU-International Journal of Electronics and Communications, 2018, vol. 83, p. 549-557. DOI: 10.1016/j.aeue.2017.11.010

[14] JILANI, S. F., ALOMAINY, A. Millimetre-wave T-shaped MIMO antenna with defected ground structures for $5 \mathrm{G}$ cellular networks. IET Microwaves, Antennas \& Propagation, 2018, vol. 12, no. 5, p. 672-677. DOI: 10.1049/iet-map.2017.0467

[15] KHATTAK, M. I., SOHAIL, A., KHAN, U., et al. Elliptical slot circular patch antenna array with dual band behaviour for future $5 \mathrm{G}$ mobile communication networks. Progress In Electromagnetics Research, 2019, vol. 89, p. 133-147. DOI: 10.2528/PIERC18101401

[16] HUSSAIN, N., JEONG, M. J., PARK, J., et al. A broadband circularly polarized Fabry-Perot resonant antenna using a single-layered PRS for 5G MIMO applications. IEEE Access, 2019, vol. 7, p. 42897-42907. DOI: 10.1109/ACCESS.2019.2908441
[17] CHASHMI, M. J., REZAEI, P., KIANI, N. Y-shaped graphenebased antenna with switchable circular polarization. Optik, 2020, vol. 200, p. 163321. DOI: 10.1016/j.ijleo.2019.163321

[18] LUDWIG, R. RF Circuit Design: Theory \& Applications. 2nd ed., Noida (India): Pearson Education India, 2009. ISBN: 9788131762189

[19] PATANVARIYA, D. G., CHATTERJEE, A., KOLA, K. S. Highgain and circularly polarized fractal antenna array for dedicated short range communication systems. Progress In Electromagnetics Research, 2020, vol. 101, p. 133-146. DOI: 10.2528/PIERC20020706

[20] CST-MICROWAVE STUDIO. CST Computer Simulation Technology AG. [Online] Cited 2020-8-08. Available at: https://www.3ds.com/products-services/simulia/products/cststudio-suite/

[21] ROGERS CORPORATION. Roges Corporation. [Online] Cited 2012-08-08. Available at: www.rogerscorp.com

[22] TOH, B. Y., CAHILL, R., FUSCO, V. F. Understanding and measuring circular polarization. IEEE Transactions on Education, 2003, vol. 46, no. 3, p. 313-318. DOI: 10.1109/TE.2003.813519

[23] MOHARRAM, M. A., KISHK, A. A. MIMO antennas efficiency measurement using wheeler caps. IEEE Transactions on Antennas and Propagation, 2015, vol. 64, no. 3, p. 115-1120. DOI: 10.1109/TAP.2015.2513420

[24] WIESBECK, W., ADAMIUK, G., STURM, C. Basic properties and design principles of UWB antennas. Proceedings of the IEEE, 2009, vol. 97, no. 2, p. 372-385. DOI: $10.1109 /$ JPROC.2008.2008838

[25] SORGEL, W., WIESBECK, W. Influence of the antennas on the ultra-wideband transmission. EURASIP Journal on Advances in Signal Processing, 2005, vol. 2005, no. 3, p. 843268. DOI: 10.1155/ASP.2005.296

\section{About the Authors ...}

Deven G. PATANVARIYA received his M.Tech. degree in VLSI (Electronics and Communication Engineering) from the National Institute of Technology Goa in 2017. He is currently working as an Institute research scholar in ECE department at NITGoa, India. His areas of interest include application of fractal antenna array and DGS integrated microstrip patch antennas, analysis and characterization of printed antennas for wireless communications.

Anirban CHATTERJEE received his M.Tech and Ph.D. from the National Institute of Technology, Durgapur, India in 2009 and 2013, respectively. Presently, he is working as an Assistant Professor in the department of ECE at the National Institute of Technology Goa, Farmagudi, Ponda, Goa, India. His research interest includes array antennas, soft computing, and image frequency rejection techniques in modern receiver systems. He has published 17 research papers in international journals and 8 papers in international conferences. He has received Gandhian Young Technological Innovation (GYTI) appreciation award in 2019. 